Polymer Journal, Vol. 5, No. 3, pp 278-282 (1973).

\title{
Molecular Weight Distribution of Polystyrene Formed in Cationic "Two-Counterion" Systems
}

\author{
Toshinobu Higashimura and Toshio Masuda \\ Department of Polymer Chemistry, Kyoto University, \\ Yoshida, Sakyo-ku, Kyoto 606, Japan.
}

(Received May 7, 1973)

\begin{abstract}
In order to study the strength of the connection between a propagating carbenium ion and its counterion, the cationic polymerization of styrene was performed in the presence of two kinds of catalysts $\left(\mathrm{SnCl}_{4}\right.$ and $\left.\mathrm{AcClO}_{4}\right)$ or of a catalyst and a salt (e.g., $\mathrm{SnCl}_{4}$ and $n$ - $\mathrm{Bu}_{4} \mathrm{NClO}_{4}$ ), and the molecular-weight distribution of the polymer obtained was examined. The molecular-weight distributions of the polystyrene obtained in methylene chloride or in a mixture of methylene chloride and benzene consisted of more than one peak. This suggests that two propagating ends whose counterions are different coexist by the simultaneous use of two catalysts and produce polymers independently without interchanging their counterions. "Two-counterion polymerization" will be defined ás the polymerization in which one kind of monomer propagates through two propagating ends with different counterions.
\end{abstract}

KEY WORDS Cationic Polymerization / Two-Counterion System /

Styrene / Molecular-Weight Distribution / Gel Permeation Chroma-

tography / Propagating End / Tetra- $n$-Butylammonium Perchlorate /

The presence of a counterion is one of the characteristics in cationic polymerization, but is not the case for radical polymerization. The counterion has great influence on the propagation reaction in cationic polymerization. This is confirmed by the large effect of the catalyst on the rate constant ratios involving the propagation rate constant $k_{\mathrm{p}}$, such as the monomer transfer constant ratio and the monomer reactivity ratio, and on the structure of the polymer produced. Thus, the influence of a counterion is found in many aspects of cationic polymeri,zation, but there have been few unequivocal studies about the state of a propagating end. This is in contrast with anionic polymerization, in which the existence of various ionic species is confirmed and the propagation rate constants are measured for each ionic species.

The counterion in cationic polymerization always contains a catalyst fragment (in a strict sense, "initiator" should be used instead of "catalyst" which is not consumed during the reaction). Therefore, it is probable that two kinds of counterions exist at the same time when a monomer is polymerized in the presence of two kinds of catalysts. The same result is ex- pected from a combination of a catalyst and a neutral salt, since an acid and a salt can easily interchange their ions in a solution. In the presence of two kinds of counterions, the following propagating species may exist corresponding to the dissociation of a propagating carbenium ion and a counterion:

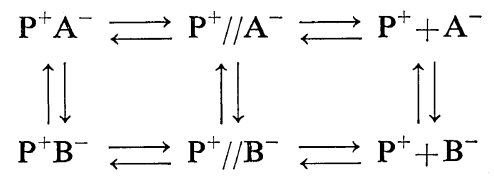

Here, $\mathrm{P}^{+} \mathrm{X}^{-}, \mathrm{P}^{+} / / \mathrm{X}^{-}$, and $\mathrm{P}^{+}+\mathrm{X}^{-}$represent, respectively, a contact ion pair (or involving nonionic species), a solvent-separated ion pair, and free ions whose counterion is $\mathrm{X}^{-}$. If a counterion exists in the neighborhood of a propagating end and the exchange of a counterion (the reactions in the longitudinal direction in eq 1 is slow enough compared with the propagation reaction, then the two kinds of active species propagate independently. Consequently, a mixture of polymers having different structures or properties will be produced. On the other hand, either in the case that the exchange of a counterion is rapid enough, or in the case that the 
propagating end is a free ion and unaffected by a counterion, a polymer with a homogeneous structure or property will be obtained.

It has been reported that the interchange of ion pairs between $N, N$-dimethylanilinium $p$ toluenesulfonate and acetate is very rapid in acetic acid. ${ }^{1}$ It is, however, not clear how fast the ion pairs involved in the ionic polymerizations interchange. Therefore, it would be very interesting to obtain information about the interchange of ion pairs in a polymerization system.

As is well known, copolymerization is a polymerization in which two kinds of monomers react with the propagating ends consisting of one kind of counterion. This concept is extended to "two-counterion polymerization." That is, two-counterion polymerization is defined as a polymerization in which one kind of monomer reacts. with two kinds of propagating ends composed of the same carbenium ion but of two different counterions. It will be of great interest to see if different polymers are produced under various conditions in such two-counterion polymerization.

In this paper, making use of molecular-weight distribution (MWD) as an observable polymer property, the possibility is investigated that the propagation reaction in the cationic polymerization of styrene proceeds independently through two kinds of active species.

\section{EXPERIMENTAL}

Acetyl perchlorate $\left(\mathrm{AcClO}_{4}\right)$ was synthesized as described elsewhere. ${ }^{2}$ Tetra- $n$-butylammonium perchlorate $\left(n-\mathrm{Bu}_{4} \mathrm{NClO}_{4}\right)$ was synthesized from tetra- $n$-butylammonium iodide and perchloric acid. ${ }^{3}$ Other catalysts (stannic chloride $\left(\mathrm{SnCl}_{4}\right)$ and boron trifluoride diethyl etherate $\left(\mathrm{BF}_{3} \mathrm{OEt}_{2}\right)$ ), solvents (methylene chloride, nitrobenzene and benzene), and styrene were purified by the usual methods.

Polymerization was performed at $0^{\circ} \mathrm{C}$ under a dry nitrgen atmosphere with an initial monomer concentration of $1.00 \mathrm{M}$. The reaction was stopped at a conversion of $40-60 \%$.

The MWD was measured by gel permeation chromatography. The chromatograms were obtained with a Shimadzu GPC Model-2A fitted with five columns of cross-linked polystyrene gel having pore sizes of $10^{1}, 10^{2}, 10^{3}, 10^{4}$, and $10^{5} \AA$. Samples were submitted for analysis as $0.15-\mathrm{g} /$ $\mathrm{d} l$ solutions in tetrahydrofuran.

\section{RESULTS}

\section{MWD of Polystyrenes Produced in Cationic Poly- merization}

Two typical examples of the MWD of polystyrene obtained in cationic polymerization are shown in Figure 1. The polymerization catalysts for Figures $1 \mathrm{a}$ and $1 \mathrm{~b}$ were $\mathrm{BF}_{3} \mathrm{OEt}_{2}$ and $\mathrm{AcClO}_{4}$, respectively. The former is a typical metal halide and the latter does not include a
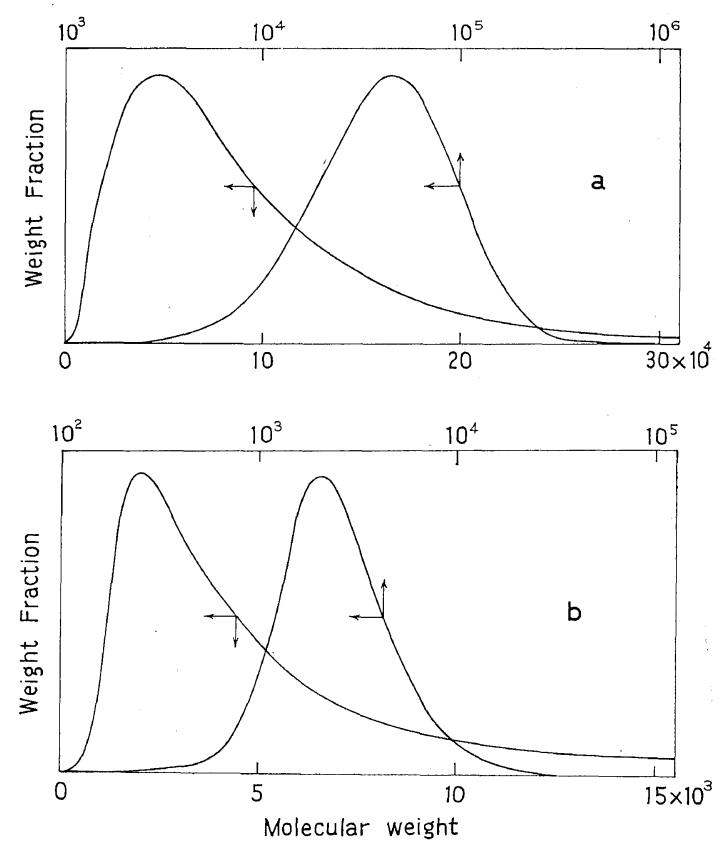

Figure 1. MWD of polystyrene catalyzed by $\mathrm{BF}_{3} \mathrm{OEt}_{2}$ and $\mathrm{AcClO}_{4}$ in methylene chloride: a, $\left[\mathrm{BF}_{3} \mathrm{OEt}_{2}\right] \quad 5.0 \mathrm{mM} ; \mathrm{b}, \quad\left[\mathrm{AcClO}_{4}\right] \quad 0.37 \mathrm{mM}$, $\left[n \mathrm{Bu}_{4} \mathrm{NClO}_{4}\right] 1.0 \mathrm{~m} M$.

metal. In the case of $\mathrm{AcClO}_{4}$, an excess of $n-\mathrm{Bu}_{4} \mathrm{NClO}_{4}$ was added; such an addition changes the MWD of the formed polymer from a bimodal distribution to a unimodal one, as reported previously. ${ }^{4}$ In both cases the solvent was methylene chloride. The molecular weights of the polystyrenes thus obtained are very different from each other, but both MWD curves are represented by a unimodal 


\section{T. Higasaimura and T. Masuda}

exponential distribution function. In the latter curve the $M_{w} / M_{n}$ value is 1.9 , which means that the curve is approximated the most probable distribution function. A similar distribution has been obtained when stannic chloride with an equimolar trichloroacetic acid as a cocatalyst $\left(\mathrm{SnCl}_{4} \cdot \mathrm{TCA}\right)$ was employed as a catalyst. It is thought that only one kind of propagating species exists in these systems.

\section{Two-Counterion Polymerization in Methylene Chloride}

The MWD of the polymer obtained in methylene chloride by $\mathrm{SnCl}_{4}$ (a trace of water in the system may work as a cocatalyst) has a single peak with a gentle slope on the low-molecularweight side (Figure 2, curve a). When a trace of $n-\mathrm{Bu}_{4} \mathrm{NClO}_{4}$ is allowed to remain in the polymerization system, the MWD becomes very broad, and seems to be composed of two peaks (Figure 2, curves $b-d$ ). In the presence of still

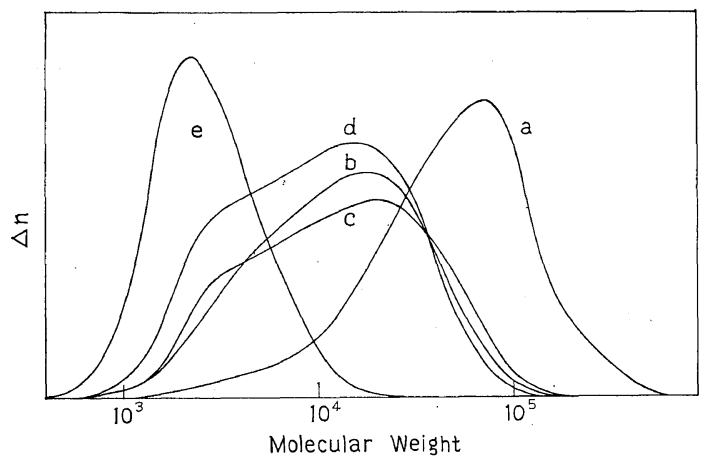

Figure 2. MWD of polystyrene obtained by $\mathrm{SnCl}_{4}$ in the presence of $n-\mathrm{Bu}_{4} \mathrm{NClO}_{4}$ in methylene chloride: $\left[\mathrm{SnCl}_{4}\right] 5.0 \mathrm{~m} M ;\left[n-\mathrm{Bu}_{4} \mathrm{NClO}_{4}\right], \mathrm{m} M: \mathrm{a}$, $0.0 ; \mathrm{b}, 0.25 ; \mathrm{c}, 0.50 ; \mathrm{d}, 1.0 ; \mathrm{e}, 5.0$.

more $n-\mathrm{Bu}_{4} \mathrm{NClO}_{4}$, the MWD reduces to a single peak in a different molecular-weight region from that without the salt (Figure 2, curve e). This MWD coincides well with that of the polystyrene formed by a combination of $\mathrm{AcClO}_{4}$ and $n-\mathrm{Bu}_{4} \mathrm{NClO}_{4}$ (see Figure 1b).

When $\mathrm{SnCl}_{4}$ is used without $n-\mathrm{Bu}_{4} \mathrm{NClO}_{4}$, a single propagating species is formed, and consequently the polymer obtained shows a unimodal MWD (curve a). The low-molecular-weight peak in curves b-d seems to be associated with the perchlorate ion. The high-molecular-weight peak, however, does not coincide with curve a. This might be explained as follows: coexistence of $\mathrm{SnCl}_{4}$ and the perchlorate ion will lead to the formation of a complex which is capable of behaving as a counterion. If a propagating species which includes the complex-type counterion is reactive enough compared with the counterion formed from $\mathrm{SnCl}_{4}$ and water, the peak corresponding to curve a will vanish. In fact, the addition of a small amount of $n$ $\mathrm{Bu}_{4} \mathrm{NClO}_{4}$ to the $\mathrm{SnCl}_{4}$ catalyst system brings about a large acceleration of the reaction rate, as was previously described. ${ }^{2}$ In the case where $\mathrm{SnCl}_{4}$ is used with an equimolar $n-\mathrm{Bu}_{4} \mathrm{NClO}_{4}$, the MWD of the polymer shows a single peak, which means that counterions other than the perchlorate ion no longer exist (curve e).

In order to demonstrate the above inference, styrene was polymerized by a mixture of $\mathrm{SnCl}_{4}$ and $\mathrm{AcClO}_{4}$. The polymerization rate at $\left[\mathrm{SnCl}_{4}\right]=10 \mathrm{~m} M$ is about the same as that at $\left[\mathrm{AcClO}_{4}\right]=0.5 \mathrm{mM}$. When a mixture of $\mathrm{SnCl}_{4}$ $(5.0 \mathrm{mM})$ and $\mathrm{AcClO}_{4}(0.25 \mathrm{mM})$ is used as a catalyst, the polymerization proceeds about 50 times as quickly as those in which both catalysts were used independently. The MWD of the polystyrene formed are very broad, with peaks

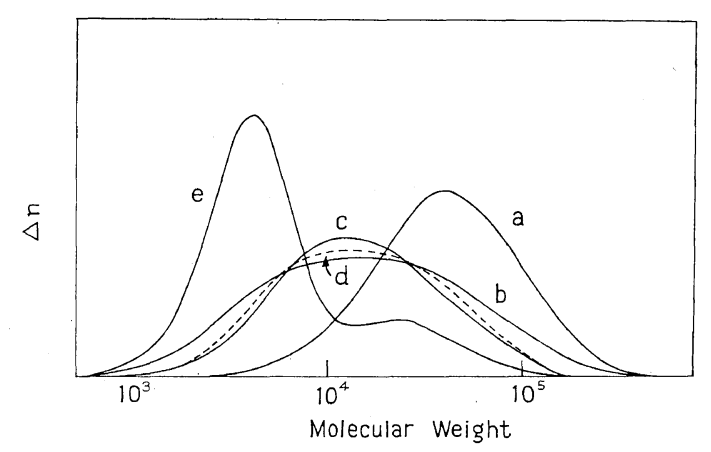

Fignre 3. MWD of polystyrene obtained by a mixture of $\mathrm{SnCl}_{4}$ and $\mathrm{AcClO}_{4}$ in methylene chloride: $\left[\mathrm{SnCl}_{4}\right], \mathrm{m} M: \mathrm{a}, 10.0 ; \mathrm{b}, 7.5 ; \mathrm{c}, 5.0 ; \mathrm{d}$, 2.5; e, 0.0. $\left[\mathrm{AcClO}_{4}\right], \mathrm{mM}: \mathrm{a}, 0.0 ; \mathrm{b}, 0.12 ; \mathrm{c}, 0.25$; d, 0.37 ; e, 0.50 .

situated in a position intermediate between the peaks for each catalyst (Figure 3, curves b-d). The position of these peaks is about the same as those of the polymers obtained by $\mathrm{SnCl}_{4}$ and $n-\mathrm{Bu}_{4} \mathrm{NClO}_{4}$ (Figure 2, curves b-d). This con- 
firms the formation of a reactive propagating end from $\mathrm{SnCl}_{4}$ and perchlorate. The wide MWD of curves $b-d$ in Figure 3 may be caused by the presence of three different active species, i.e., a complex-type counterion formed from $\mathrm{AcClO}_{4}$ and $\mathrm{SnCl}_{4}$, and two kinds of counterions from $\mathrm{AcClO}_{4}$.

Next, polymers obtained by $\mathrm{BF}_{3} \mathrm{OEt}_{2}$ in the presence of $n-\mathrm{Bu}_{4} \mathrm{NClO}_{4}$ were examined. Both the MWD with $n-\mathrm{Bu}_{4} \mathrm{NClO}_{4}$ equivalent to the catalyst and without $n-\mathrm{Bu}_{4} \mathrm{NClO}_{4}$ are unimodal, though their average molecular weights are very different (Figure 4, curves a and c). In the

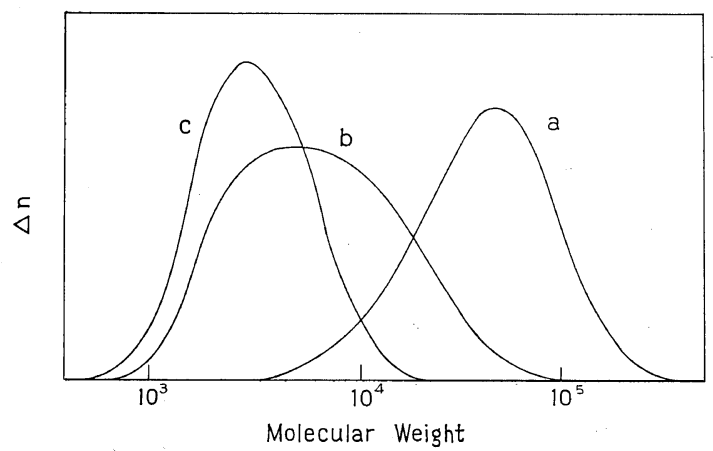

Figure 4. MWD of polystyrene obtained by $\mathrm{BF}_{3} \mathrm{OEt}_{2}$ in the presence of $n-\mathrm{Bu}_{4} \mathrm{NClO}_{4}$ in methylene chloride: $\left[\mathrm{BF}_{3} \mathrm{OEt}_{2}\right] 5.0 \mathrm{mM} ;\left[n-\mathrm{Bu}_{4} \mathrm{NClO}_{4}\right]$, $\mathrm{m} M:$ a, $0.0 ; \mathrm{b}, 0.50 ; \mathrm{c}, 5.0$.

presence of $n-\mathrm{Bu}_{4} \mathrm{NClO}_{4} \quad 1 / 10$ equivalent to the catalyst, the polymer has a broad MWD, probably consisting of two peaks as shown in curve b. These peaks seem to correspond to curve c and a peak at a middle position between curves $\mathrm{a}$ and $\mathrm{c}$.

From these results, it is concluded that two active species whose counterions are $\mathrm{MX}_{n} \cdot \mathrm{ClO}_{4}{ }^{-}$ and $\mathrm{ClO}_{4}^{-}$, propagate separately when an adequate amount of $n-\mathrm{Bu}_{4} \mathrm{NClO}_{4}$ or $\mathrm{AcClO}_{4}$ is used together with metal halide $\left(\mathrm{MX}_{n}\right)$.

Two-Counterion Polymerizations in Nitrobenzene and in a Mixture of Methylene Chloride and Benzene

A phenomenon was found, as described in the above section, that two kinds of propagating species yield polymers of different molecular weights separately in methylene chloride. It was investigated whether this holds also in

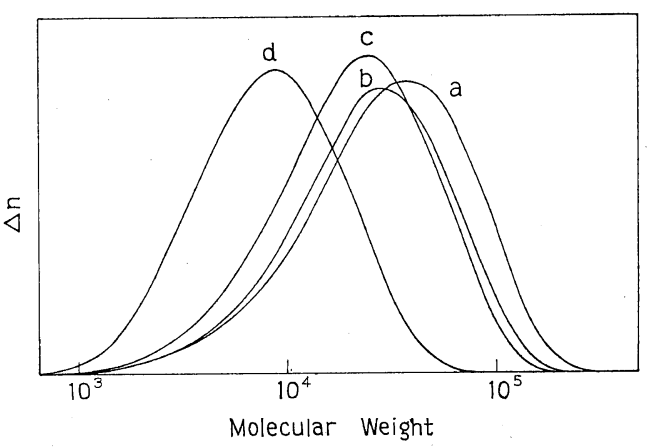

Figure 5. MWD of polystyrene formed by $\mathrm{SnCl}_{4}$ in the presence of $n-\mathrm{Bu}_{4} \mathrm{NClO}_{4}$ in nitrobenzene: [ $\left.\mathrm{SnCl}_{4}\right] 5.0 \mathrm{mM} ;\left[n-\mathrm{Bu}_{4} \mathrm{NClO}_{4}\right], \mathrm{m} M:$ a, $0.0 ; \mathrm{b}$, 0.25 ; c, $0.50 ; \mathrm{d}, 5.0$.

nitrobenzene as a solvent, since it has a greater polarity. In Figure 5 are shown the MWD of polystyrene obtained by $\mathrm{SnCl}_{4}$ in the coexistence of $n-\mathrm{Bu}_{4} \mathrm{NClO}_{4}$ in nitrobenzene solution. In this case, despite the change in the quantity of $n$ $\mathrm{Bu}_{4} \mathrm{NClO}_{4}$, the broadness of the MWD hardly varies. Merely average molecular weight decreases with the increase in the concentration of $n-\mathrm{Bu}_{4} \mathrm{NClO}_{4}$. The possibility that two molecularweight peaks are overlapping is clearly denied.

In the polymerization catalyzed by $\mathrm{SnCl}_{4}$ in nitrobenzene, the addition of $n-\mathrm{Bu}_{4} \mathrm{NClO}_{4}$ leads to the change in average molecular weight of the polymer. Furthermore, the presence of $n$ $\mathrm{Bu}_{4} \mathrm{NClO}_{4}$ more than the amount of $\mathrm{SnCl}_{4}$ results into an identical MWD with that yielded by $\mathrm{AcClO}_{4}$ under the same conditions. This indicates that a counterion has bearing on propagation reaction also in nitrobenzene. It can, however, be said that the influence of counterion is rather small, as the molecular weight does not change so largely with the addition of the salt as in methylene chloride. Moreover, the broadness of the MWD is unaffected by the quantity of the added salt. Hence, it is concluded that a counterion is relatively loosely connected and exchanges rapidly enough during propagation reaction in nitrobenzene as a solvent.

When benzene is used as a nonpolar solvent, most of the polymer formed in the presence of $n-\mathrm{Bu}_{4} \mathrm{NClO}_{4}$ is a methanol-soluble oligomer. Therefore, a mixture of methylene chloride and benzene ( $3: 1 \mathrm{vol}$ ratio) was used as a nonpolar 


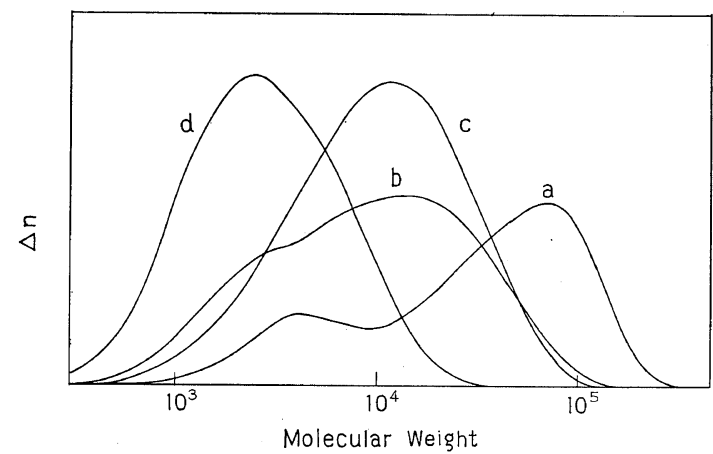

Figure 6. MWD of polystyrene formed by $\mathrm{SnCl}_{4}$ in the presence of $n-\mathrm{Bu}_{4} \mathrm{NClO}_{4}$ in a mixture of methylene chloride and benzene (3:1 vol ratio): $\left[\mathrm{SnCl}_{4}\right] 5.0 \mathrm{~m} M ;\left[n-\mathrm{Bu}_{4} \mathrm{NClO}_{4}\right], \mathrm{m} M:$ a, $0.0 ;$ b, $0.25 ; \mathrm{c}, 0.50 ; \mathrm{d}, 5.0$.

solvent. The dependence of MWD on the concentration of $n-\mathrm{Bu}_{4} \mathrm{NClO}_{4}$ is shown in Figure 6 . Without the salt, the MWD is bimodal, which suggests that an aggregate ion exists as one of counterions. When the added salt is equivalent to the amount of $\mathrm{SnCl}_{4}$, the MWD (curve d) coincides with that obtained using $\mathrm{AcClO}_{4}$ as catalyst under the same conditions. If $n$ $\mathrm{Bu}_{4} \mathrm{NClO}_{4} 1 / 10$ as much as the catalyst is present, the reaction is accelerated and MWD shows a single peak (curve c). This indicates that a complex. formed by $\mathrm{SnCl}_{4}$ and prechlorate ion is a principal counterion in the system.

\section{DISCUSSION}

When a polymerization is performed in methylene chloride solution in the presence of two kinds of catalysts $\left(\mathrm{SnCl}_{4}\right.$ and $\left.\mathrm{AcClO}_{4}\right)$ or under the coexistence of a catalyst and a salt $\left(\mathrm{SnCl}_{4}\right.$ and $n-\mathrm{Bu}_{4} \mathrm{NClO}_{4}$ ), the produced polystyrenes possessed a bimodal MWD. The peaks of the MWD seem to correspond to those of the poly- styrenes formed with $\mathrm{ClO}_{4}^{-}$and $\mathrm{SnCl}_{4} \cdot \mathrm{ClO}_{4}^{-}$as counterions. This is the first example of a polymerization in which two kinds of propagating ends grow separately in a homogeneous system. Clearly, this system can be called a two-counterion polymerization, as defined in the introductory section.

If two ion pairs propagate separately in methylene chloride, the use of a more polar solvent will give rise to a change in the MWD owing to the increase in the interchange rate and/or the dissociation to free ions. As expected, the polystyrene obtained in nitrobenzene shows a MWD consisting of a single peak. It was rather difficult to obtain a clear result in a less polar solvent, such as a mixture of benzene and methylene chloride, since the interaction between $\mathrm{SnCl}_{4}$ and $\mathrm{ClO}_{4}^{-}$became strong.

As was described in the introductory section, it is generally accepted that the interchange rate of two ion pairs is very large. Taking account of this, it is surprising and very important that the independent coexistence of two species was observed in the polymerization systems of this study. Further investigations are necessary to determine the reasons why two kinds of propagating ends grow independently under some conditions.

\section{REFERENCES}

1. E. Grunwald and M. S. Puar, J. Amer. Chem. Soc., 89, 6842 (1967).

2. a) V. Jaacks and W. Kern, Makromol. Chem., 62, 1 (1963).

b) T. Masuda and T. Higashimura, J. Macromol. Sci.-Chem., A5, 549 (1971).

3. T. Masuda and T. Higashimura, J. Polym. Sci., Part $A-1$, 9, 1563 (1971).

4. T. Masuda and T. Higashimura, ibid., Part B, 9, 783 (1971). 